\title{
Roles of Protein Kinase A (PKA) and PKC on Corticotropin- Releasing Hormone (CRH)-Induced Elevation of Cytosolic Calcium from Extra- and Intra-cellular Sources
}

\author{
Irini Dermitzaki ${ }^{1}$, Christos Tsatsanis ${ }^{1}$, Vassiliki-Ismini Alexaki ${ }^{2}$, Elias Castanas $^{2}$, \\ Andrew N. Margioris ${ }^{1}$
}

${ }^{1}$ Departments of Clinical Chemistry-Biochemistry, ${ }^{2}$ Experimental Endocrinology, School of Medicine, University of Crete, Heraklion, Crete GR-710 03, Greece

\begin{abstract}
Corticotropin-releasing hormone $(\mathrm{CRH})$ affects cytosolic calcium ion levels. The aim of the present work was to examine the role of protein kinase A (PKA)- and PKC-dependent signalling pathways in mediating the effect of CRH on calcium ion influx (from extra-cellular sources) and calcium ion mobilization (from intra-cellular stores). In this study, we employed a well-known model of neural crest-derived cells, the PC12 rat pheochromocytoma cell line. We found that CRH increased the concentration of cytosolic calcium ions in calcium-rich and in calcium-free media. In both conditions, an inhibitor of PKA phosphorylation abolished the effect of CRH. In contrast, the inhibitor of PKC phosphorylation blocked the effect of CRH only in calcium-free conditions. The phorbol ester PMA, activator of PKC, accelerated the steep of the curve of cytosolic calcium ion increase from intracellular stores. These data suggest that: (a) CRH induces calcium ion entrance into the cytoplasm from both extra-cellular sources (influx) and from intra-cellular stores (mobilization); (b) the PKAdependent signalling pathway mediates both effects of $\mathrm{CRH}$; and (c) the PKC-dependent signalling pathway mediates only the CRH-induced mobilization of calcium ions from intra-cellular stores. Thus, this is the first report demonstrating that distinct signalling pathways control the effects of $\mathrm{CRH}$ on calcium ion influx and on calcium ion mobilization from intra-cellular stores.
\end{abstract}

Key words: Calcium signalling, Corticotropin-Releasing Hormone, PKA, PKC, PC12 Pheochromocytoma

Address correspondence and requests for reprints to: Andrew N. Margioris, Department of Clinical Chemistry Biochemistry, School of Medicine, University of Crete, Heraklion GR-710 03, Crete, Greece, Tel: 30-2810-323474 and 30-2810-394588, Fax: 30-2810-394581,

e-mails: andym@med.uoc.gr and renaderm@med.uoc.gr

Received 01-09-04, Revised 20-09-04, Accepted 25-09-04
ABBREVIATIONS

$\mathrm{CRH} \quad$ corticotropin-releasing hormone

PKC protein kinase $\mathrm{C}$

PKA protein kinase $\mathrm{A}$

PMA phorbol 12-myristate 13-acetate

CRHR1 CRH type 1 receptor 


\section{INTRODUCTION}

The fluctuations of cytosolic calcium ion levels represent part of signalling pathways through which extracellular signals affect cellular functions including exocytosis, gene expression, contraction, and programmed cell death (apoptosis). Cytosolic calcium ions derive from two sources: (a) from influx of extra-cellular calcium, either via voltage-gated or ligand-dependent channels, and (b) from the mobilization of calcium from intra-cellular stores, the most significant of which is the endoplasmic reticulum.

It is now well established that calcium ion signalling pathways mediate a significant number of the biological effects of corticotropin releasing hormone $(\mathrm{CRH})$ and these effects are possibly of particular importance with regard to cell function. It was initially shown that CRH induces calcium ion influx in AtT20 corticotroph cells possibly via the PKC signalling pathway $^{1}$. It was later shown that the effect of CRH on ACTH secretion is largely dependent on calcium ion influx through activation of voltage-gated L-type $\mathrm{Ca}$ ion channels, an effect accompanied by a simultaneous CRH-mediated induction of the expression of these channels ${ }^{2}$. Similarly, the relaxing activity of $\mathrm{CRH}$ on ileal smooth muscle cells appears to involve mobilization of calcium ions from intracellular stores within the sarcoplasmic reticulum ${ }^{3}$. This effect of $\mathrm{CRH}$ appears to be mediated also by a PKA-dependent signalling pathway. Furthermore, $\mathrm{CRH}$ inhibits receptor-mediated intracellular calcium responses in a locus coeruleus-like cell line, the CATH.a, an effect involving $\mathrm{PKA}^{4}$. In addition, $\mathrm{CRH}$ induces cell shape changes in invertebrate immunocytes via both the PKA and PKC signalling pathways ${ }^{5,6}$ while sauvagine [a CRH type 1 receptor (CRHR1) and CRHR2 receptor agonist] induces the mobilization of calcium ions from intracellular stores ${ }^{7}$. Finally, the inhibitory effect of CRH on the proliferation of mouse melanoma cells is mediated by the CRHR1 receptor and involves calcium ion signalling 8 .

Classically, CRH stimulates the expression as well as the secretion of ACTH in rat anterior pituitary corticotrophs and in the murine AtT-20 cell line via the Gs - adenyl cyclase - cAMP - PKA signalling pathway. However, it has been established that $\mathrm{CRH}$ also affects the $\mathrm{Gq}$ - phospholipase C-inositol 1,4,5-trisphosphate - PKC pathway in pituitary, Leydig cells, adrenals, placenta, immunocytes, myometrium, and in the hippocampus ${ }^{5,-11}$. Furthermore, it has been shown that in human epidermoid cells, CRH induces the activity as well as the translocation of PKC isoenzymes $^{12}$. Finally, exposure of neuroblastoma cells to phorbol esters, activators of PKC, results in up-regulation of $\mathrm{CRH}$ binding sites suggesting an additional mechanism through which the PKC signalling pathway may modulate some of the biological effects of $\mathrm{CRH}^{13}$.

Based on the data mentioned above, it has been hypothesized that the effect of CRH on cytosolic calcium ion levels may be mediated by either the PKA or the PKC signalling pathways. It should be noted that a recent report states that this may be true for the $\operatorname{skin}^{14}$. Indeed, in corticotroph cells, although PKA mediated the stimulatory effect of dBcAMP and forskolin on calcium ion influx (through voltage-gated $\mathrm{Ca}$ ion channels), it only partially mediated the effect of $\mathrm{CRH}$, giving the impression that the effect of $\mathrm{CRH}$ on calcium ion influx may be also mediated by a cAMP-independent mechanism $^{5,15}$. Thus, it has been proposed that $\mathrm{CRH}$ stimulates calcium ion influx, mainly via L-type Ca ion channels. The observed calcium ion influx, which is independent of action potentials (membrane depolarization) and mediated by PKC, may involve P-type calcium ion channels ${ }^{16}$.

The aim of the present work was to elucidate the role of the PKA and PKC signalling pathways in the mediation of the stimulatory effect of $\mathrm{CRH}$ on cytosolic ion levels from extra-cellular and intra-cellular calcium ion sources. In this study, we employed a wellknown model of neural crest-derived cells, the PC12 rat pheochromocytoma cell line. Our data advance a novel hypothesis regarding the effect of CRH on calcium ion trafficking.

\section{MATERIALS AND METHODS}

\section{Reagents and Antibodies}

Rat/human recombinant CRH was purchased from Sigma Chemicals Co. (St. Louis, MO). The inhibitor of PKC phosphorylation, the pseudo-substrate myristoylated alanine-rich PKC[20-28] (Myr-N-FARKGALRQ- $\mathrm{NH}_{2}$ ) and the inhibitor of PKA phosphorylation, myristoylated PKA[14-22] (Myr-GRTGRRNAI-NH2) were obtained from Calbiochem (La Jolla, CA) while the activator of conventional and novel PKC isoenzymes, phorbol 12-myristate 13-ace- 
tate (PMA), was purchased from Sigma. The inhibitor of the conventional PKC isoenzymes $\mathrm{PKC} \alpha / \beta$ is a pseudosubstrate sequence from PKC $\alpha$ and $P K C \beta$ that is $\mathrm{N}$-terminal myristoylated to allow membrane permeability. The inhibitor of PKC $\alpha / \beta$ specifically inhibits TPA activation of MARCKS phosphorylation in fibroblast primary cultures (IC50 $=8 \mu \mathrm{M})$. The inhibitor exhibits $98 \%$ inhibition at $100 \mu \mathrm{M}$. RPMI Medium 1640, L-glutamine, HEPES, penicillin/ streptomycin, horse serum and fetal calf serum (FCS) were purchased from Gibco (Gibco-BRL Co, MD), while bovine serum albumin (BSA) was obtained from Sigma. All sterile tissue apparatus were obtained from Corning (NY, NY). All other chemicals and reagents were obtained from Sigma, unless stated otherwise.

\section{The PC12 rat pheochromocytoma cell line}

PC12 cells were obtained from two sources: Dr. M. Greenberg (Children's Hospital, Boston, MA, U.S.A.), and the American Type Culture Collection (Rockville, MD, USA). Cells were grown in RPMI Medium 1640 containing $10 \mathrm{mM}$ L-glutamine, $15 \mathrm{mM}$ HEPES, $100 \mathrm{U} / \mathrm{ml}$ penicillin, $0.1 \mathrm{mg} / \mathrm{ml}$ streptomycin, $10 \%$ horse serum and $5 \% \mathrm{FCS}$ at $5 \% \mathrm{CO}_{2}$ and $37^{\circ} \mathrm{C}$. One day before the experiment, the initial culture media were changed with serum-free media supplemented with $0.1 \%$ BSA.

\section{Measurement of cytosolic calcium ions}

PC12 were detached from culture flasks by vigorous shaking, washed and resuspended in $\mathrm{Ca}^{2+}$ medium $(140 \mathrm{mM} \mathrm{NaCl}, 5 \mathrm{mM} \mathrm{KCl}, 1 \mathrm{mM} \mathrm{MgCl}, 2 \mathrm{mM}$ $\mathrm{CaCl}_{2}, 10 \mathrm{mM}$ Hepes, $5 \mathrm{mM}$ D-glucose) at a cell density of 0.5 million per ml. Subsequently, they were incubated for $30 \mathrm{~min}$ at $25^{\circ} \mathrm{C}$ in the dark with $5 \mu \mathrm{M}$ Fura 2/ AM (Molecular Probes, Leiden, the Netherlands), centrifuged (1500xg, $10 \mathrm{~min})$, resuspended in either calcium rich or calcium free media (without calcium ions plus 1mM EGTA, final concentration of calcium ions is less than $0.1 \mathrm{nM}$ ), and transferred to quartz cuvettes. Fluorescence was measured at time intervals of $10 \mathrm{sec}$ at two excitation wavelengths $(340 \mathrm{~nm}$ and $380 \mathrm{~nm})$ and a single emission wavelength (510 $\mathrm{nm}$ ) with a Perkin Elmer LS-3B Fluorescence Spectrometer. Cytosolic calcium ion responses were expressed as the ratio of peak fluorescence intensities (measured at $510 \mathrm{~nm}$ ) produced by Fura 2 using excitation wavelengths of 340 and $380 \mathrm{~nm}$. In its free form, Fura 2 has high excitation efficiency at $380 \mathrm{~nm}$ and low excitation efficiency at $340 \mathrm{~nm}$. With calcium bound, the reverse is true: at $380 \mathrm{~nm}$ Fura 2 fluoresces with low excitant efficiency and at $340 \mathrm{~nm}$ with high excitant efficiency. This ratio $(340 \mathrm{~nm}$ over $380 \mathrm{~nm}$ fluorescence intensities) is an index of calcium concentration. Therefore, changes in calcium concentration are expressed as change in ratio units (DR). The fluorescence ratios are directly proportional to the absolute calcium concentrations.

\section{RESULTS}

\section{Effect of $C R H \pm P K A$ or PKC inhibitors on calcium ion influx}

The effect of CRH on calcium ion influx from extra-cellular sources was examined in the first set of experiments in which PC12 cells were incubated in calcium ion rich media and subsequently exposed to $\mathrm{CRH}$. The measurement of cytosolic calcium ion levels started within seconds following the application of $\mathrm{CRH}$ and continued for $1500 \mathrm{sec}$. Figure 1, panel A depicts the effect of CRH at $1 \mathrm{nM}$ which induced an acute elevation of cytosolic calcium ions. Figure 1, panel D depicts the effect of the simultaneous presence of the PKA phosphorylation inhibitor myristoylated PKA[14-22] at $100 \mu \mathrm{M}$ on $\mathrm{CRH}$-induced calcium ion elevation in PC12 cells in a calcium rich environment. Indeed, the PKA inhibitor prevented the stimulatory effect of CRH suggesting that PKA-dependent signalling pathways mediate its effect. Compared to $\mathrm{CRH}$ alone, the simultaneous presence of the activator of PKC phorbol 12-myristate 13-acetate (PMA) at $200 \mathrm{nM}$ (Figure 1, panel B) or of the PKC phosphorylation inhibitor pseudo-substrate myristoylated alanine-rich PKC[20-28] at $100 \mu \mathrm{M}$ (Figure 1, panel E) did not significantly alter the steep of the curve depicting the rate of cytosolic calcium ion elevation suggesting that the PKC signalling pathway was not part of the CRH-induced calcium ion influx.

\section{Effect of $C R H \pm P K A$ or PKC inhibitors on the mobilization of calcium ions from intracellular stores}

The effect of CRH on the mobilization of calcium ion from intra-cellular sources was examined in the first set of experiments in which PC12 cells were cultured in calcium ion free media and subsequently exposed to CRH. Figure 2, panel A depicts the effect of $\mathrm{CRH}$ at $1 \mathrm{nM}$ which induced an elevation of cytosolic 


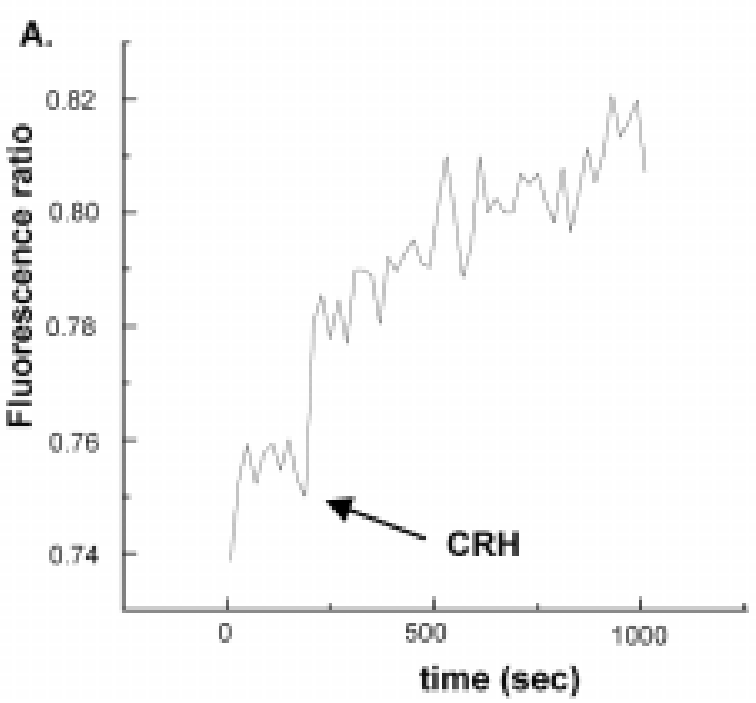

B.

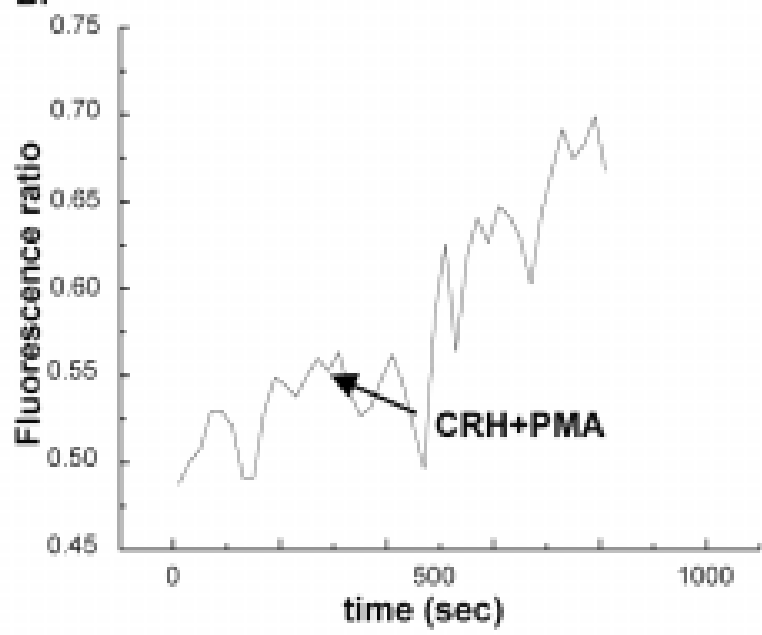

D.

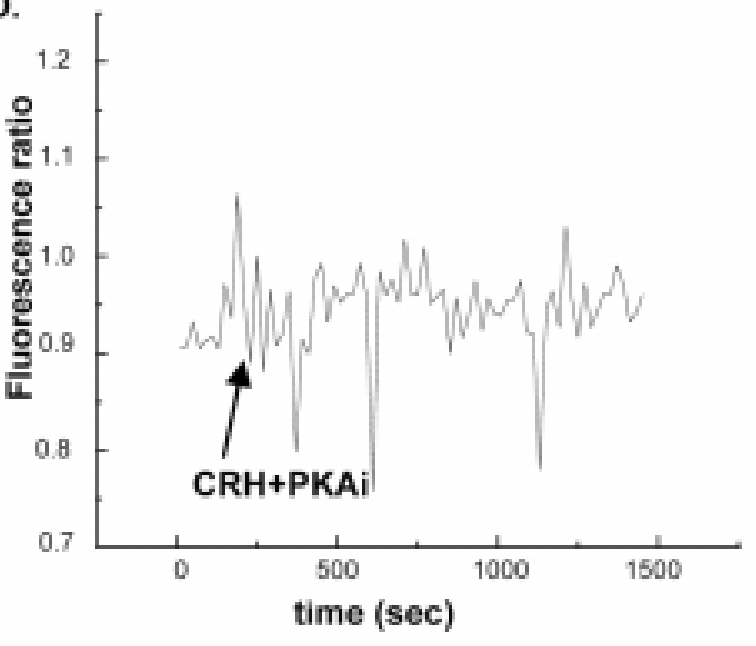

calcium ions. Figure 2, panel $\mathrm{C}$ depicts the effect of the simultaneous presence of the PKC activator PMA at $200 \mathrm{nM}$ which augmented the steep of the curve depicting the rate of cytosolic calcium ion elevation suggesting that the PKC signalling pathway plays a major role in the mobilization of calcium ions from intracellular stores. The additive effect of $\mathrm{CRH}$ and PMA occurs instantly indicating that PMA targets signalling components downstream of the CRH receptors, possibly $\mathrm{PKC}$, that rapidly mobilise $\mathrm{Ca}$ ions release (Figure 2, panel B). Figure 2, panel D depicts the effect of the PKA inhibitor at $100 \mu \mathrm{M}$ on CRHinduced calcium ion elevation in PC12 cells in a calcium free environment. The PKA inhibitor prevented

c.

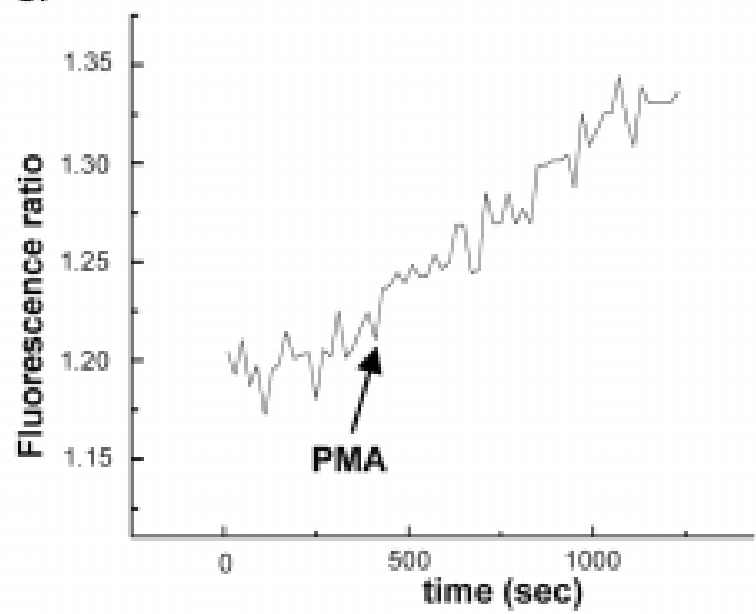

E.

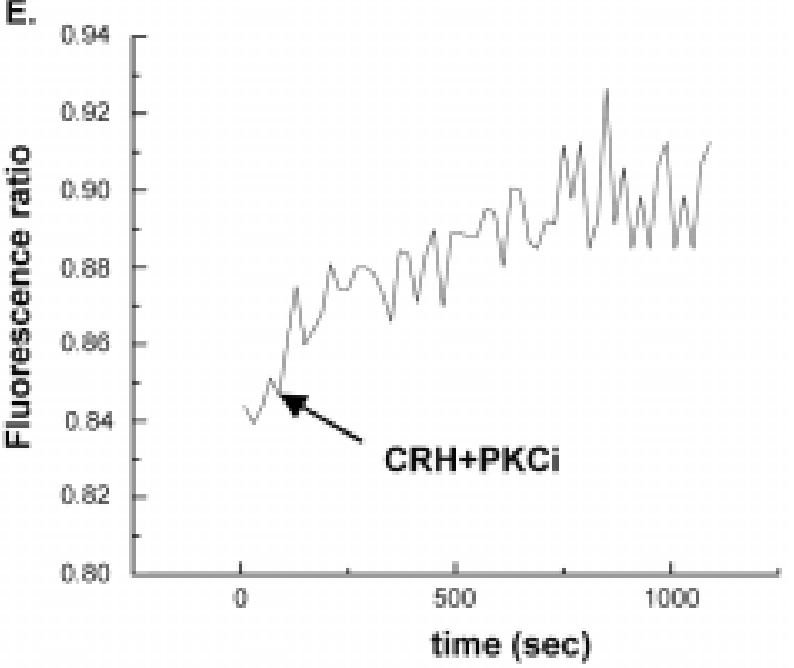

Figure 1. Effect of CRH on calcium ion influx from extra-cellular sources. Panel A depicts the effect of CRH at $1 \mathrm{nM}$. Panel B depicts the effect of CRH + PMA at $200 \mathrm{nM}$. Panel C depicts the effect of PMA at $200 \mathrm{nM}$. Panel D depicts the effect of CRH + the PKA inhibitor at 100 $\mu \mathrm{M}$. Panel E depicts the effect of $\mathrm{CRH}+\mathrm{PKC}$ inhibitor at $100 \mu \mathrm{M}$. Cytosolic calcium ion levels were measured for 1500 sec. The arrows indicate the time point at which the stimulus was applied on the cells. 
completely the stimulatory effect of $\mathrm{CRH}$ suggesting that PKA-dependent signalling pathways mediate the effect of CRH. Figure 2, panel E depicts the effect of

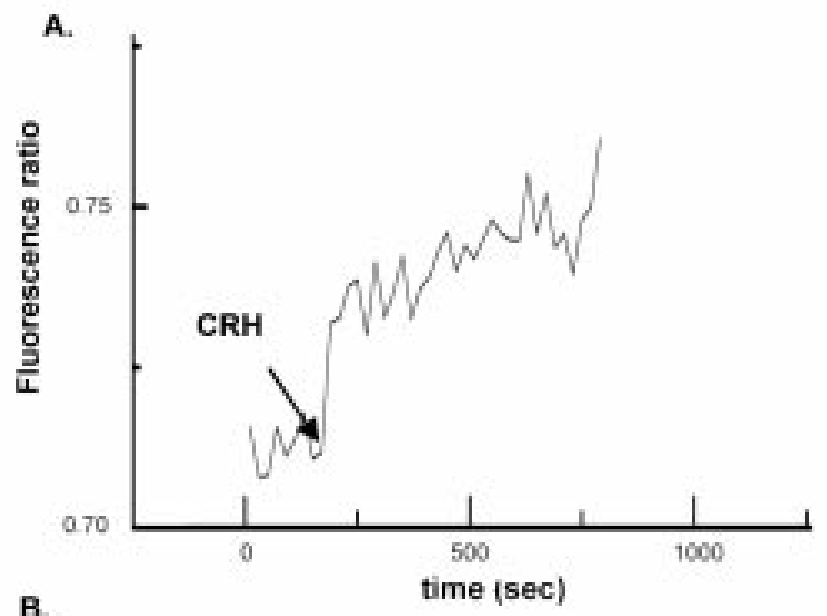

B.

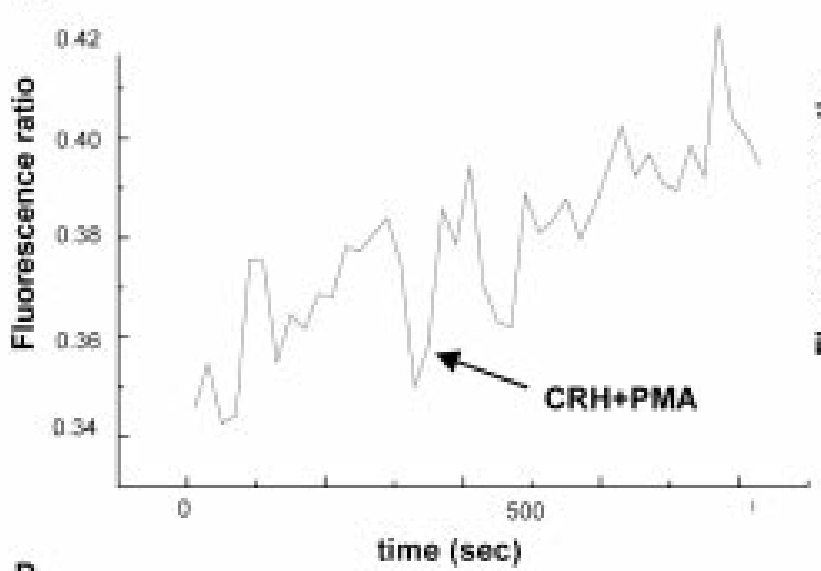

D.

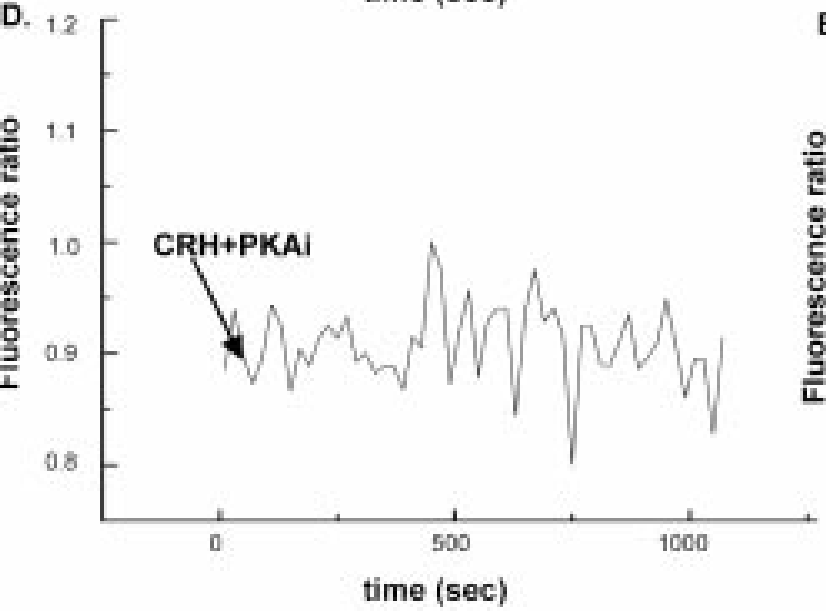

the PKC inhibitor at $100 \mu \mathrm{M}$ on $\mathrm{CRH}$-induced elevation of cytosolic $\mathrm{CRH}$ from intra-cellular stores i.e. in a calcium free environment. The PKC inhibitor blocked completely the effect of CRH suggesting that the PKC signalling pathway mediates the effect of $\mathrm{CRH}$ on calcium ion mobilization from intra-cellular sources.

Taken together, the above mentioned two sets of experiments on the effect of $\mathrm{CRH}$ on calcium rich (Figure 1) or calcium free (Figure 2) environments indicate that while the PKA signalling pathway mediates the stimulatory effect of CRH on both calcium ion influx and calcium ion mobilization from intracellular sources, the PKC signalling pathway mediates only the latter.
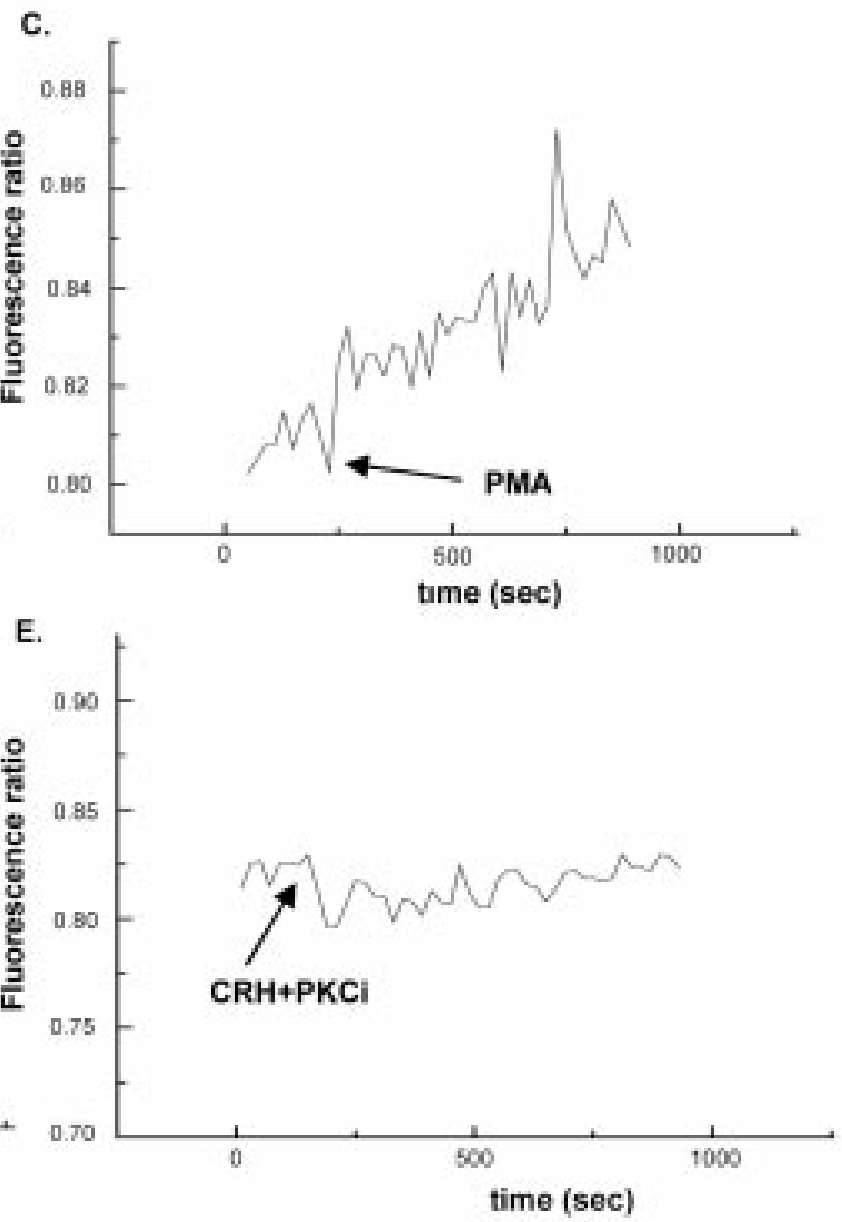

Figure 2. Effect of CRH on calcium ion influx from intra-cellular sources. Panel A depicts the effect of CRH at $1 \mathrm{nM}$. Panel B depicts the effect of CRH + PMA at $200 \mathrm{nM}$. Panel C depicts the effect of PMA at $200 \mathrm{nM}$. Panel D depicts the effect of CRH + the PKA inhibitor at 100 $\mu \mathrm{M}$. Panel E depicts the effect of CRH + PKC inhibitor at $100 \mu \mathrm{M}$. Cytosolic calcium ion levels were measured for 1500 sec. The arrows indicate the time point at which the stimulus was applied on the cells. 


\section{DISCUSSION}

We found that $\mathrm{CRH}$ induces the entrance of calcium ions into the cytoplasm from (a) extra-cellular sources (via induction of its cellular influx) and (b) intra-cellular sources (via calcium ion mobilization from intra-cellular sources the most important of which is the endoplasmic reticulum). To this point, our data are in agreement with published reports showing that CRH induces calcium ion entrance from extra-cellular ${ }^{2,5,15-18}$ and/or intra-cellular sources ${ }^{3,6,7,15,16,19,20}$.

We have further detected that PKA and PKC signalling pathways play distinct roles in $\mathrm{CRH}$-induced elevation of cytosolic calcium ions. Indeed, our data suggest that the PKA-dependent pathway mediates both effects of CRH i.e. the induction of calcium ion influx as well as its mobilization from intracellular stores while the PKC-dependent pathway appears to be associated only with the mobilization of calcium ions from intracellular stores. It should be noted here that classically, the adenyl cyclase - cAMP - PKA signalling pathway was associated with the influx of extra-cellular calcium ions (either via voltage-gated or ligand-dependent channels) while the phospholipase C (PLC) - PIP2 - IP3 - IP3 receptor (located on the endoplasmic reticulum) was associated with the mobilization of calcium ions from intracellular stores ${ }^{21}$. The exact role and significance of the PLC - PIP2 DAG - PKC pathway is uncertain. During the last few years it has been shown that $\mathrm{CRH}$ affects calcium ion trafficking mainly via the PKA-dependent signalling pathway ${ }^{4,15,22}$, although the PKC signalling pathway was also associated with calcium ion influx from extra-cellular sources, possibly via a P-type calcium ion channel ${ }^{5,16}$. Our findings clearly demonstrate for the first time that the effect of $\mathrm{CRH}$ on extra-cellular calcium ion influx is mediated exclusively by the PKA signalling pathway. Indeed, the PKC pathway is not involved in CRH-induced extra-cellular calcium ion influx. In addition, we found that the effect of $\mathrm{CRH}$ on calcium ion mobilization from intra-cellular sources appears to be mediated by both the PKA and the PKC signalling pathways.

We previously published our findings showing that CRH induces PC12 cell apoptosis via the PKC signalling pathway ${ }^{23}$. We now report that CRH mobilizes cytosolic calcium ions from intracellular sources via the same signalling pathway. It has been shown that calcium ion mobilization from the endoplasmic retic- ulum activates cell death cascades via calcium ion influx into the mitochondria, which releases cytochrome $\mathrm{c}$, and by calcium ion influx into the nucleus, where it participates in the apoptotic process. This is accomplished by induction of apoptotic gene transcription, caspase activation, and nuclear DNA fragmentation ${ }^{24}$. Indeed, the calcium-mediated pathways appear to be extremely important in neuronal cell apoptosis ${ }^{25}$. Thus, our data on CRH-induced mobilization of intracellular calcium ions via PKC and its effect on apoptosis via the same signalling pathway strengthens the hypothesis that CRH may be associated with neuro-degenerative diseases.

\section{ACKNOWLEDGMENT}

This work was supported by a grant (PENED 01ED386) from the Hellenic Secretariat for Research and Technology.

\section{REFERENCES}

1. Reisine T, 1989 Phorbol esters and corticotropin releasing factor stimulate calcium influx in the anterior pituitary tumor cell line, AtT-20, through different intracellular sites of action. J Pharmacol Exp Ther 248: 984-90.

2. Xie J, Nagle GT, Childs GV, Ritchie AK, 1999 Expression of the L-type $\mathrm{Ca}(2+)$ channel in AtT-20 cells is regulated by cyclic AMP. Neuroendocrinology 70:1-9.

3. Duridanova DB, Petkova-Kirova PS, Lubomirov LT, Gagov H, Boev K, 1999 Corticotropin-releasing hormone acts on guinea pig ileal smooth muscle via protein kinase A. Pflugers Arch 438: 205-12.

4. Bundey RA, Kendall DA, 1999 Inhibition of receptormediated calcium responses by corticotrophin-releasing hormone in the CATH.a cell line. Neuropharmacology 38: 39-47.

5. Malagoli D, Franchini A, Ottaviani E, 2000 Synergistic role of cAMP and IP(3) in corticotropin-releasing hormone-induced cell shape changes in invertebrate immunocytes. Peptides 21: 175-82.

6. Tse A, Lee AK, 2000 Voltage-gated Ca2+ channels and intracellular $\mathrm{Ca} 2+$ release regulate exocytosis in identified rat corticotrophs. J Physiol 528 Pt 1: 79-90.

7. Rossant CJ, Pinnock RD, Hughes J, Hall MD, McNulty S, 1999 Corticotropin-releasing factor type 1 and type 2alpha receptors regulate phosphorylation of calcium/ cyclic adenosine 3', 5'-monophosphate response elementbinding protein and activation of p42/p44 mitogen-activated protein kinase. Endocrinology 140: 1525-36.

8. Carlson KW, Nawy SS, Wei ET, et al, 2001 Inhibition of mouse melanoma cell proliferation by corticotropin-releasing hormone and its analogs. Anticancer Res 21: 1173-9.

9. Chakravorty A, Mesiano S, Jaffe RB, 1999 Corticotro- 
pin-releasing hormone stimulates P450 17alpha-hydroxylase/17,20-lyase in human fetal adrenal cells via protein kinase C. J Clin Endocrinol Metab 84: 3732-8.

10. Grammatopoulos DK, Randeva HS, Levine MA, Katsanou ES, Hillhouse EW, 2000 Urocortin, but not corticotropin-releasing hormone $(\mathrm{CRH})$, activates the mitogen-activated protein kinase signal transduction pathway in human pregnant myometrium: an effect mediated via R1alpha and R2beta CRH receptor subtypes and stimulation of Gq-proteins. Mol Endocrinol 14: 2076-91.

11. Blank T, Nijholt I, Grammatopoulos DK, Randeva HS, Hillhouse EW, Spiess J, 2003 Corticotropin-releasing factor receptors couple to multiple G-proteins to activate diverse intracellular signaling pathways in mouse hippocampus: role in neuronal excitability and associative learning. J Neurosci 23: 700-7.

12. Kiang JG, Wang X, McClain DE, 1994 Corticotropin-releasing factor increases protein kinase $\mathrm{C}$ activity by elevating membrane-bound alpha and beta isoforms. Chin $\mathrm{J}$ Physiol 37: 105-10.

13. Dieterich KD, DeSouza EB, 1996 Functional corticotropin-releasing factor receptors in human neuroblastoma cells. Brain Res 733: 113-8.

14. Pisarchik A, Slominski A, 2004 Molecular and functional characterization of novel CRFR1 isoforms from the skin. Eur J Biochem 271: 2821-30.

15. Kuryshev YA, Childs GV, Ritchie AK, 1995 Corticotropin-releasing hormone stimulation of $\mathrm{Ca} 2+$ entry in corticotropes is partially dependent on protein kinase A. Endocrinology 136: 3925-35.

16. Kuryshev YA, Childs GV, Ritchie AK, 1996 Corticotropin-releasing hormone stimulates $\mathrm{Ca} 2+$ entry through $\mathrm{L}$ and P-type $\mathrm{Ca} 2+$ channels in rat corticotropes. Endocrinology 137: 2269-77.

17. King MS, Baertschi AJ, 1990 The role of intracellular messengers in adrenocorticotropin secretion in vitro. Ex- perientia 46: 26-40.

18. Shorten PR, Robson AB, McKinnon AE, Wall DJ, 2000 $\mathrm{CRH}$-induced electrical activity and calcium signalling in pituitary corticotrophs. J Theor Biol 206: 395-405.

19. Spada A, Reza-Elahi F, Lania A, Bassetti M, Atti E, 1990 Inhibition of basal and corticotropin-releasing hormonestimulated adenylate cyclase activity and cytosolic $\mathrm{Ca} 2+$ levels by somatostatin in human corticotropin-secreting pituitary adenomas. J Clin Endocrinol Metab 70: 1262-8.

20. Yamamori E, Iwasaki Y, Oki Y, et al, 2004 Possible involvement of ryanodine receptor-mediated intracellular calcium release in the effect of corticotropin-releasing factor on adrenocorticotropin secretion. Endocrinology 145: $36-8$.

21. Siegel GJ, Agranoff BW, Albers RW, Fisher SK, Uhler MD, 1999 In: Basic Neurochemistry: Molecular, Cellular, and Medical. In. American Society for Neurochemistry

22. McFerran BW, Guild SB, 1996 The roles of adenosine 3',5'-cyclic monophosphate-dependent protein kinase A and protein kinase $\mathrm{C}$ in stimulus-secretion coupling in AtT-20 cells. J Mol Endocrinol 16: 133-40.

23. Dermitzaki E, Tsatsanis C, Gravanis A, Margioris AN, 2002 Corticotropin-releasing hormone induces Fas ligand production and apoptosis in PC12 cells via activation of p38 mitogen-activated protein kinase. J Biol Chem 277: 12280-7.

24. Boehning D, Patterson RL, Snyder SH, 2004 Apoptosis And Calcium: New Roles For Cytochrome c And Inositol 1,4,5-Trisphosphate. Cell Cycle 3: 252-254.

25. Ferreiro E, Oliveira CR, Pereira C, 2004 Involvement of endoplasmic reticulum $\mathrm{Ca} 2+$ release through ryanodine and inositol 1,4,5-triphosphate receptors in the neurotoxic effects induced by the amyloid-beta peptide. J Neurosci Res 76: 872-80. 